\title{
El espejo del retrato: el conde de Rebolledo y sus dedicatarias ${ }^{\mathrm{I}}$
}

\author{
Rocío CÁRdenas LunA \\ Pedro Ruiz Pérez \\ Universidad de Córdoba
}

\begin{abstract}
El análisis de la propuesta iconográfica y discursiva de los retratos de Rebolledo y de sus dedicatarias incluidos en sus textos parte de la consideración de la naturaleza misma del proyecto editorial del conde y su relación con una trayectoria vital de tareas diplomáticas fuera de España. En su consideración se tienen en cuenta, junto a la sistematicidad de su aparición y la singularidad del diálogo autor/dedicatario, la gramática visual de los grabados y la peculiar relación con los de las reinas de Suecia y Dinamarca. Junto a lo relativo a la afirmación autorial, se avanza la conclusión de que, frente al modelo más tradicional de relaciones que se mantiene en el retrato y la dedicatoria a Felipe IV, el diálogo con Cristina y Sofía Amalia abre renovados espacios de lectura.
\end{abstract}

Keywords: Retrato, estrategia autorial, dedicatorias, edición, Rebolledo.

Aun después de que Lope propusiera un ejemplo cimero para las relaciones entre poesía e imprenta, en el tercio central del siglo Xvir se mantiene una aún significativa reticencia a entregar a la estampa la producción lírica. Es el caso de autores tan representativos como Solís o Salazar y Torres, cuya obra solo aparece póstumamente (Ruiz Pérez 2017). Es posible que pesara, como herencia del Fénix, una marca de profesionalización no muy bien vista por los letrados (Strosetzki 1997). Tal vez por ello fueron los nobles, sin sospechas del recurso a las prensas como modus vivendi, quienes osaron romper el techo de cristal y publicar sus versos. Es el caso del príncipe de Esquilache, de Enríquez de Cabrera, de Juan de Moncayo y de algunos otros miembros del aristocrático círculo zaragozano de mediados de siglo ${ }^{2}$. Lejos del escenario hispano por su periplo europeo en misión diplomática, el conde de Rebolledo también se aparta de las prácticas habituales en la edición de poesía, y no solo publica sistemáticamente sus sucesivos volúmenes líricos, sino que incluso culmina la empresa de reordenarlos y, en el mismo año de edición de su último libro exento, compilar tres volúmenes de lo que

I El presente artículo se inscribe en el plan de trabajo del proyecto Sujeto e institución literaria en la edad moderna, FFI20I4-54367-C2-I-R del Plan Estatal de I+D+i.

2 Jiménez Belmonte (2007) revela las claves de la actitud y las razones del noble poeta amateur; en Ruiz Pérez (2017b) hay una aproximación a la práctica editorial de este Almirante de Castilla; para los autores zaragozanos puede verse Ruiz Pérez (20II y 2009b), con carácter más panorámico. 
bien puede considerarse su poesía completa. Un breve repaso a sus datos bio-bibliográficos evidencia estas circunstancias.

\section{Perfiles de una vida y despliegue de una obra}

La trayectoria biográfica de don Bernardino de Rebolledo (González Cañal I997 y 20I0; Martín Puya 20I3) está marcada por sus orígenes aristocráticos. Miembro de la baja nobleza, solo accede al título de conde tras la muerte de su hermano. Su condición le lleva al servicio del trono, y lo cumple sobre todo en los límites del imperio. A las armas suceden las tareas diplomáticas, que lo tienen casi cinco décadas en los territorios del norte de Europa, cumpliendo distintas embajadas. Sin menoscabo de su destacado papel en el desarrollo de la política imperial, manifestó continuamente sus dificultades económicas, sus penurias, incluso físicas, en las duras tierras del norte y el deseo de volver a la Península, objetivo que solo alcanzaría en el último tramo de su vida.

En este contexto, su perfil parecía el más adecuado para el desarrollo de la práctica poética como un amateur (Jiménez Belmonte 2007), al modo de los nobles citados más arriba, y en cierto modo así fue, ya que su ejercicio del verso se puso en no poco grado al servicio de sus propósitos diplomáticos y personales. Su aura de poeta debió de ser una buena carta de presentación ante los poderosos cerca de los cuales cumplió su oficio de embajador. Al mismo tiempo, su obra era una llamada de atención al entorno cortesano para propiciar su retorno, lo que no dejó de manifestar en los paratextos de sus obras, convertidas en verdadero altavoz de sus añoranzas. A la luz de los acontecimientos, cabe concluir que la poesía le fue a Rebolledo más eficaz en el primero de los planos que en el segundo.

Su obra deja huella de sus relaciones, directas o indirectas, con figuras tan destacadas en el panorama político y militar del contexto de la Guerra de los Treinta Años como la reina Cristina de Suecia y la monarca danesa Sofía Amalia de Brunswick-Lüneburg. A esta última le dedicaría sus Selvas dánicas (Copenhagen, I655) compuestas durante la estancia del poeta en el palacio de Hersholme, cedido por la soberana y convertido en materia de la silva descriptiva que constituye la segunda parte de la obra (Ruiz Pérez 20I4 y 20I5). Con la primera mantendría una relación más indirecta, participando de algún modo en las maniobras políticas que llevaron a la conversión de la reina sueca al catolicismo, con su influencia en el desarrollo de los acontecimientos bélicos.

Lo significativo de la relación de Rebolledo con la poesía es el hecho que servía de punto de partida a estas páginas. Y es que, sin poder considerarse un profesional en sentido estricto, ya que no acudía a la imprenta como modus vivendi, en busca de inmediata compensación económica, convirtió en 
un habitus (Bourdieu 1995) la sistemática publicación de sus versos, articulados en precisas y matizadas entregas. Los pies de imprenta de sus libros van dando razón de sus movimientos geográficos por Europa, apareciendo sus textos siempre fuera de España. Así se suceden, con notable regularidad y en un corto período de tiempo, los seis títulos que componen su producción: Ocios (Amberes, Oficina Plantiniana, I650), Selva militar y política (Colonia, Antonio Kinchio, 1652), La constancia victoriosa. Égloga sacra (Colonia, Antonio Kinchio, 1655), Selvas Dánicas (Copenhagen, Pedro Morsingio, I655), Selva sagrada (Colonia, Antonio Kinchio, I657) e Idilio sacro (Amberes, Oficina Plantiniana, I660). Además de la recurrencia de algunos talleres, destaca en esta relación una apreciable gradación, muy en la línea de la disposición habitual de los volúmenes de poesía en el siglo XVI, en una escala ascendente, que lleva desde las formas y materias más humildes a las más elevadas. Para Rebolledo este orden venía condicionado por la renuncia al tono jocoso, los asuntos populares y los metros tradicionales. Partía del cancionero amoroso, generalmente ubicado en el mediocris stilus, pero con el «ocio» de su denominación se situaba como la materia menos apreciable. Tras discurrir por asuntos de orden didáctico, histórico o descriptivo, culmina en los temas religiosos, que ocupan la mitad de sus títulos, incluyendo la versión poética del Libro de Job, su versión de los trenos de Jeremías y una versificación de la vida de Cristo, que culmina la serie de publicaciones.

La existencia y operatividad de una conciencia autorial que diseña una meditada «carrera literaria» llega a su extremo con el inicio, el mismo año y en la misma imprenta en que publica su último título, de la edición de unas verdaderas «obras completas» distribuidas en tres tomos. En ellos la disposición no sigue el orden cronológico de aparición de los distintos títulos. Rebolledo los reordena, y dibuja con su aparición en menos de dos años (I660-I66I) un cuidado perfil de autor y una obra meditadamente orientada hacia lo sublime, ejemplo raro si no es en las colecciones de obras póstumas, cuando el editor da por concluida la obra del poeta e interpreta su producción para resaltar su valor. Junto al interés manifestado por su sistemática estrategia editorial, en la obra de Rebolledo podemos apreciar otra significativa huella autorial.

Siguiendo también en esto el ejemplo lopesco (Sánchez Jiménez 2006), Rebolledo ofrece otro rasgo de distinción en sus volúmenes: la sistemática inclusión de retratos en sus libros, consagrando una iconografía de fuerte impronta nobiliaria, pero actuando también como una verdadera rúbrica $o$ marca autorial (Ruiz Pérez 2009), identificándose como poeta y creador de textos, como sujeto dedicado a la composición y edición de sus obras. 


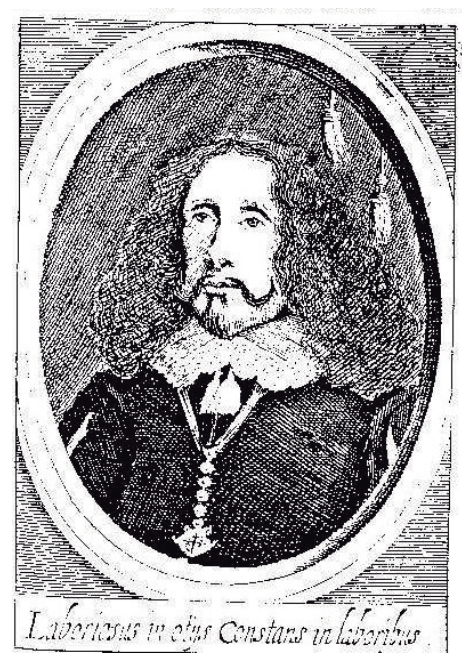

Ocios, 1650.

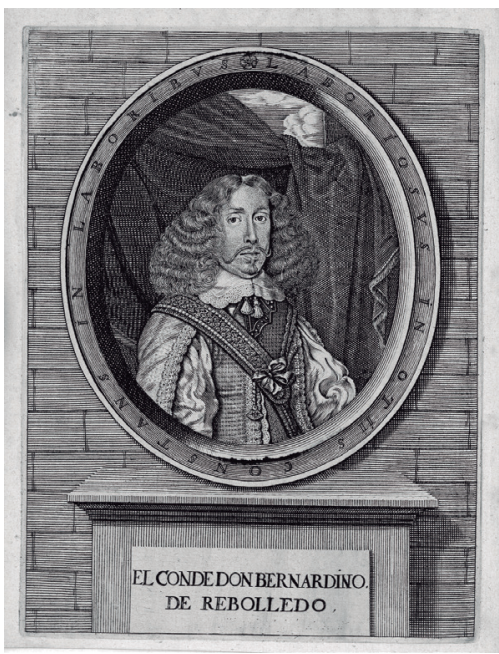

Idilio Sacro, I660.

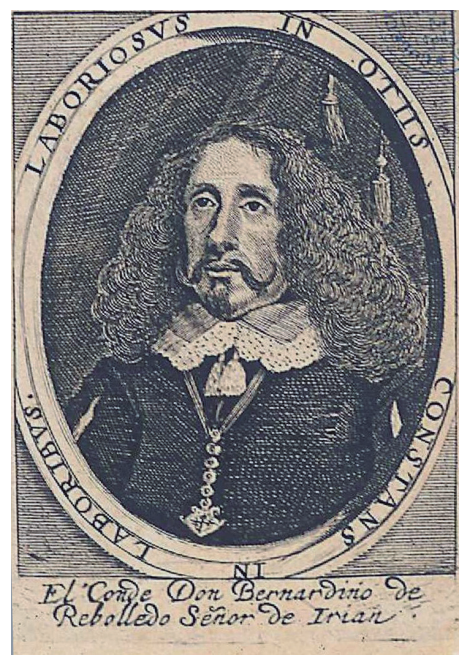

Selva militar, 1652.

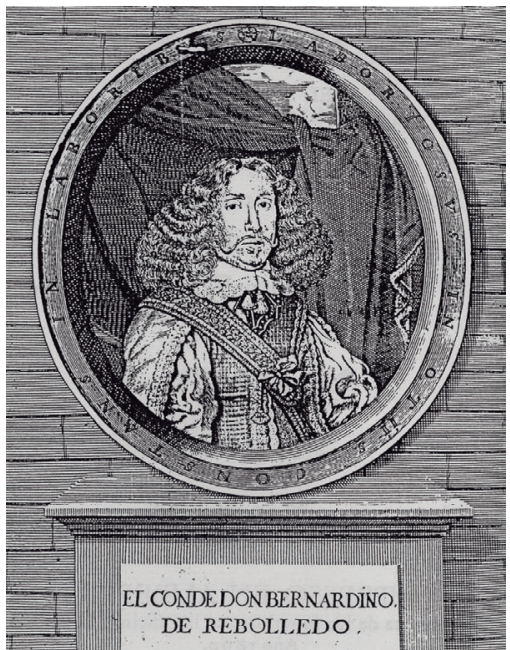

Ocios, I66o. 


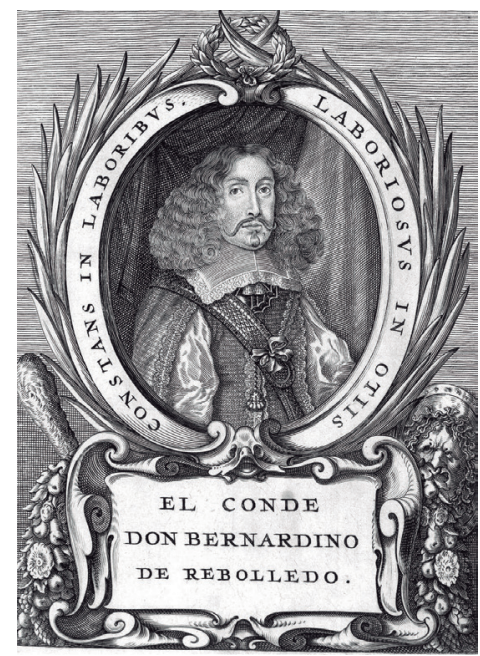

Selva militar, I66I.

Su representación iconográfica adopta los rasgos clásicos del medallón de raíz grecolatina y desarrollo humanista, adaptando la posición del torso y adoptando una disposición con ciertos aires de novedad. Su canonicidad, sin embargo, es evidente y queda demostrada por la adopción del modelo en los retratos incorporados por López de Sedano en su Parnaso español (I768I778), con la adición bajo el busto del poeta de los instrumentos emblemáticos de su arte. 


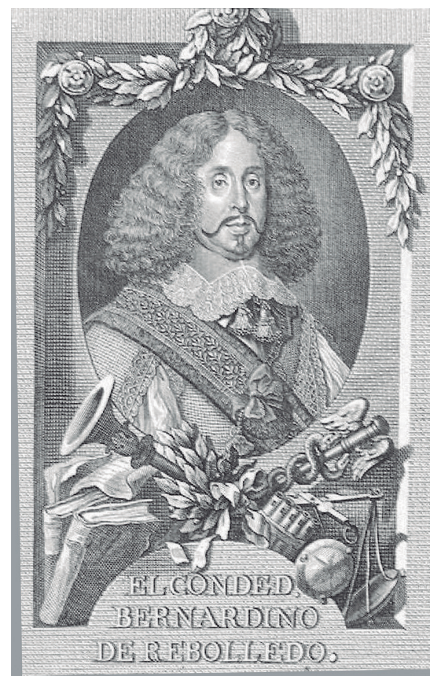

López de Sedano, Parnaso español, I77I.

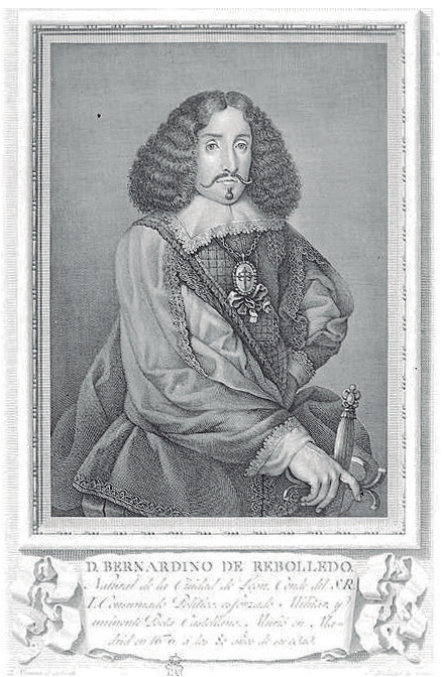

Retrato por Joaquín Ballester, I79I.

Las constantes se imponen tanto en el desarrollo de la iconografía del personaje, con muy ligeras variaciones, como en la disposición de la imagen, sancionando su valor canónico, como retrato «fidedigno» del poeta y como ejemplo de representación del aristócrata escritor.

En cambio, si pasamos de la consideración intrínseca de la imagen a su funcionamiento en el cuerpo del volumen y en la orientación de lectura que propone, apreciamos un elemento sumamente distintivo, poco habitual en los impresos poéticos del siglo, y es que también de manera constante don Bernardino acompaña sus retratos con los de las personalidades regias a quienes dedica su obra, incluso cuando en la versión final cambia de destinatario. Es el caso, por ejemplo, de la Selva militar, dedicada en 1652 al Archiduque de Austria, don Fernando, rey de Hungría y Bohemia, para dirigirse en el volumen II de la reedición antuerpiense al príncipe Felipe Próspero, en cada ocasión con el retrato grabado del dedicatario correspondiente. También se extiende en el primer volumen de las obras reunidas a la reina de Dinamarca y Noruega, Sofía Amalia de Lüneburg, la dedicatoria de Ocios, sin destinatario en la primera edición.

No faltaban casos previos en que el libro presentaba un doble retrato; sin embargo, las referencias más llamativas corresponden al diálogo visual (e intelectual) entre el poeta canonizado y su comentarista. Así lo encontramos en las Lecciones solemnes que Pellicer consagra a la obra de Góngora (I630) o en los comentarios de Faria y Sousa a Os Lusiadas de Camoens (I639, 
4r). Como en este último caso muestra la inclusión de un muy extenso «Elogio al comentador» realizado por el ya fallecido Lope de Vega, precediendo a ambos retratos, la estrategia se dirige a la equiparación de los dos escritores, representados en forma similar y como vueltos, en su simétrica posición en tres cuartos, para mantener un diálogo.

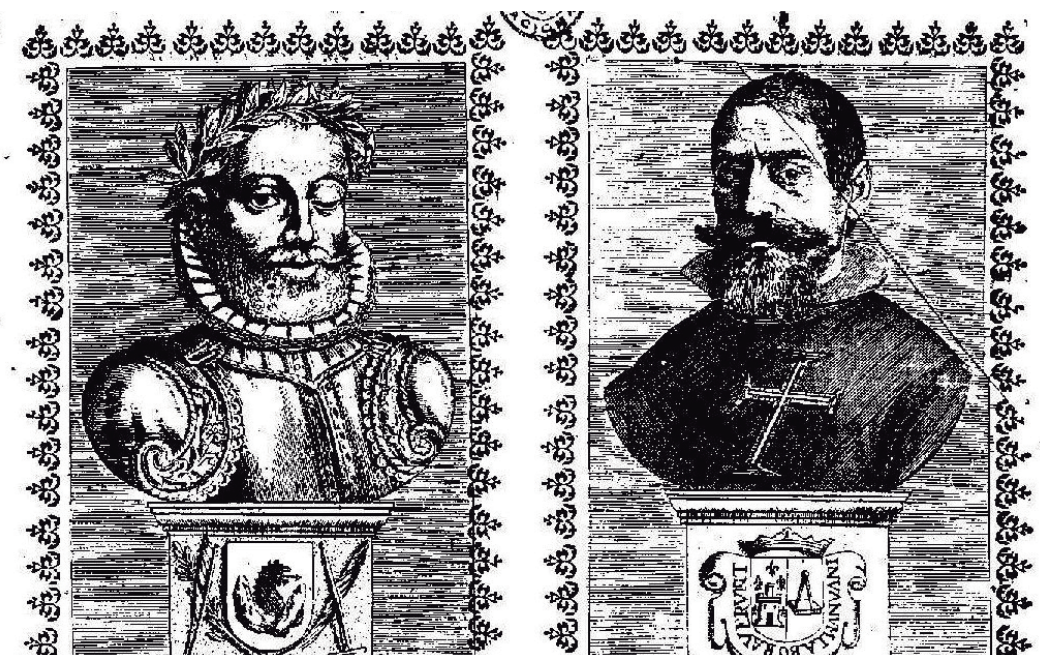

Lusiadas, Madrid, I639.

En el juego de retratos parejos Faria propone una participación en la gloria del poeta épico, si no se trata de una abierta emulación, basada en el mismo juego de desplazamientos que proponía el tópico épico: si el poeta supera al héroe por ser quien le otorga inmortalidad, el comentarista puede superar al poeta ${ }^{3}$, al esclarecer e ilustrar su obra, otorgándole rango canónico.

La notoriedad del modelo, ligada a la posición de Faria en la polémica gongorina, bien podría haber inspirado a Rebolledo, por más que en su caso (más poeta aristocrático que humanista letrado) el diálogo se establece con sus egregios destinatarios. Se suman, además, las diferencias ligadas, de un lado, al ya esbozado marco oval de su tratamiento como medallón y, de otro, a la distancia establecida en la dispositio de los respectivos retratos en páginas separadas del libro. Distinta a la del comentarista respecto al auctor era la relación que el poeta establecía con sus dedicatarios, separando la

3 Sobre la interferencia de los editores, no solo en el sentido comercial del concepto, véase Brown (1995) y Ezell (1999); la deriva del papel inicial de los humanistas en esta función de recuperación de los textos clásicos es analizada por Grafton y Jardine (1986). 
función de uno y otros. Se mantenía la voluntad de usufructo de la luz del poderoso, a modo de satélite solar, con unas pretensiones que tenían más de social (o de favor directo) que de estrictamente literario, al menos en el sentido específico de la república letrada.

Matices significativamente distintos adquiría este recurso en los libros impresos por Rebolledo.

\section{Poética y pragmática del retrato}

Desde que en el siglo Xv el retrato se convierte en género independiente al liberarse del contexto religioso y vincularse a una cultura laica y la demanda de los particulares, la producción se multiplica, aunque se mantiene vinculada a las clases dominantes: el desarrollo del arte en el contexto de las cortes nobiliarias incrementa el número de artistas plásticos especializados en esta práctica, y la consiguiente disminución de su precio permite a una clientela más amplia y variada el acceso al retrato. Todo el que se considera estimable por alguna razón se hace retratar para proclamar su existencia. Con el advenimiento de la imprenta la aparición del retrato en forma de grabados sigue un proceso similar, de la representación reservada a los auctores clásicos a la presencia del mecenas y, por último, del escritor contemporáneo en sus propios textos.

En todos los casos la aparición del retrato, también en los volúmenes impresos, representa una forma de auctoritas. A partir de la potestas que los gobernantes tratan de recoger de los emperadores romanos o de las representaciones sacras, se configura la relación entre la figuración visual del sujeto y el prestigio que le acompaña, reforzado por una imagen que implica distinción (inicialmente por su carestía), perduración y emblema de la autoridad. En el orden de las letras el valor se sanciona con los textos de los clásicos, convertidos en encarnaciones por antonomasia de una disciplina o de una modalidad genérica. Si la geometría era un Euclides o la épica un Virgilio, la efigie del autor, como en los programas iconográficos de bibliotecas como la de El Escorial, se convertía en el centro de una serie de intercambios simbólicos, al que pronto aspiraron los autores vernáculos.

Así llega a la cronología de Rebolledo una relativamente consolidada situación del acceso de los escritores a la representación de su vulto personal entre las páginas de sus impresos. Autores como Mateo Alemán o Lope de Vega los utilizarán a modo de auténtica firma, para legitimar las ediciones autorizadas de sus textos o, como en el caso particular del Fénix, para pautar su evolución física y social, concluyendo en sus retratos de senectud con el hábito religioso y caballeresco. Pesaba, no obstante, la tradición que otorgaba relevancia al dedicatario, ya fuese en su función directa de mecenazgo, ya fuese simplemente por el hecho de trasladar a la obra la autoridad 
y el prestigio vinculados al estamento nobiliario. En este contexto resultan intercambiables el retrato individual del poderoso y su escudo de armas, que remitía al conjunto del linaje y apelaba a la fuente última de relevancia y de prestigio para el autor. Cuando este no contaba con dichos elementos, debía recurrir a recibirlos del dedicatario a cambio de su homenaje.

La conexión de arte literario y axiología social (Sociología de la literatura hispánica, 2018), extendida en el reinado de los Austria, adquiere una relevancia particular cuando el autor no procede del estamento más bajo, sino que ya participa, por su cuna, del aura aristocrática. En estos casos, como el que representa nuestro poeta (aunque el caso era más frecuente en los géneros doctrinales y religiosos, más frecuentados por segundones de la nobleza), el retrato personal alternaba posiciones en los preliminares del impreso con la referencia gráfica de su linaje, en forma del escudo de su casa. Dentro de la general tendencia de Rebolledo a la reduplicación, a la saturación de elementos auráticos, no resulta extraño que en sus páginas la alternancia ceda su lugar a la convivencia, doblando el elemento de prestigio del retrato con la impresión de su emblema nobiliario.

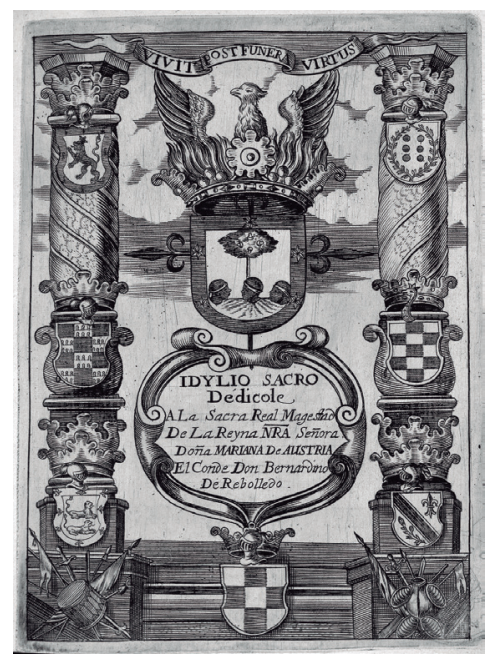

Idilio sacro, 1600.

Peculiaridad del conde poeta, la insistencia en el recurso gráfico para una función más profunda que la mera ornamentación del impreso, demuestra, a la vez que su conciencia estamental, la de su papel como autor y nos obliga a atender a la relevancia de su representación, incluida la forma que adopta y los elementos con que se conforma, base del diálogo que establece, como veremos, con los destinatarios de sus textos. Conviene, pues, 
comenzar por una sintética gramática visual de la efigie autorial que consagra la reiteración.

Todas las representaciones de Rebolledo que aparecen en sus textos son grabados de busto del escritor en edad adulta, representado en tres cuartos con la mirada fija en el espectador. El conde se encuentra centrado y dominando la composición, mostrando su imagen como figura relevante y merecedora de reconocimiento. Aunque las representaciones parecen partir de una imagen común y mantienen la misma iconografía, hay elementos diferenciadores de relevancia. El primer retrato conocido, el de la edición de Ocios, se encuentra enmarcado en una orla conmemorativa a modo de medallón clásico que se acerca al lenguaje iconográfico grecolatino, convertido en constante en las representaciones posteriores, siempre inscribiendo el lema latino usado por don Bernardino: Laboriosus in otiis, constans in laboribus. El tratamiento impone también una cierta sobriedad en la representación, aunque este rasgo se irá diluyendo con el paso del tiempo, hasta llegar a la más recargada imagen de la edición de I66I de la Selva militar. En la composición más repetida se presenta enmarcado en su orla sin mayor ornamentación que un texto que testimonia su condición, además de estar elevado sobre un pedestal en el que aparece su nombre y título aristocrático. Su imagen física y su atuendo también se repiten, con pelo largo y cuidado, lazos y gran cuello de camisa a la moda de la época, exhibiendo su linaje nobiliario. La actitud que muestra es la de un hombre seguro de sí mismo, con pose señorial y serena. En la serie de grabados más constante el personaje se encuentra en una habitación con grandes cortinas, que dejan entrever una salida al exterior, metáfora de la creación. Atrás quedan los retratos de sus dos primeras ediciones, con una representación más prototípica de un caballero sin rasgos distintivos y sin hacer ninguna referencia a su perfil de escritor. Solo destaca el escudo que aparece en su pecho, y también se omite la ambientación de la representación, pues la orla se aprieta en torno al busto, excluyendo todo elemento que pueda sugerir la creatividad o el aura del artista. En la imagen de Ocios la orla aparece desnuda, relegando el lema al pie del retrato. Al desaparecer en la composición de la Selva militar, alguien anotó a mano la filiación del poeta, destacando su posición social, al reunir el título nobiliario y el señorío.

Volviendo a lo apuntado acerca de la más que posible influencia de esta representación en el modelo adoptado en la colección de López de Sedano ${ }^{4}$, puede ser de interés volver a los dos retratos ajenos a la estrategia editorial del propio poeta. Mientras el dibujo de Rafael Ximeno ratifica el éxito del modelo iconográfico en la representación del poeta, la estampa grabada por

4 Viene al caso recordar el papel del Conde en el elenco de autoridades escogido por la Real Academia de la Lengua para ilustrar las entradas de su diccionario, con lo que implica de reconocimiento del prestigio del autor. 
Manuel Salvador Carmona para el tomo V del Parnaso español revela en la traslación del modelo la similitud adoptada por el resto de las representaciones gráficas de los petas antologados. En las palabras de López de Sedano, la descripción física de nuestro autor reproduce, con expresa mención, los datos transmitidos por las semblanzas grabadas en sus libros: «Fue el Conde de Rebolledo, según muestra su retrato, de hermosa presencia y gran gentileza personal, alto y gallardo de cuerpo, el rostro hermoso, blanco, grueso y prolongado, aspecto grave, majestuoso y halagüeño, los ojos vivos, los labios gruesos, el cabello largo y abundante» (I77I, xxix). Por su parte, el ilustrador dieciochesco retoma la disposición plástica, incluyendo la orla y el pedestal con el nombre, convertidos en rasgos comunes de la serie. La alusión a la lírica y la épica, con la lira y la trompa, correponde también a la gramática instituida para la colección a partir de los habituales topoi.

El breve repaso nos permite constatar cómo el retrato de Rebolledo se fija y mantiene una continuidad iconográfica en sus distintas obras y reediciones, lo que denota una clara estrategia de autorización que tiene como base la reiteración de la representación y de su forma. Los rasgos, además, permiten inscribir su gramática, más que en la retórica canonizadora adoptada por Quevedo en su Parnaso español o en la creciente tendencia a representar al poeta en el acto de escribir o con los instrumentos de su labor, en una axiología de orden aristocrático, que toma la posición social como principio supremo de valor, de modo que junto a la exaltación del autor se produce la del estamento al que pertenece y el del orden que sustenta. Recordemos la inclusión de su escudo de armas como otro elemento en este discurso.

En el régimen de la Monarquía Hispánica la literatura se imbrica frecuentemente con la política y aparece en todo caso muy teñida de sus condicionamientos sociales. La situación se acentúa en el contexto personal de Rebolledo, por su linaje y por su servicio diplomático. Al igual que Saavedra Fajardo, quiso dejar constancia de los avatares europeos de su desempeño en su producción escrita. A diferencia del autor de las Locuras de Europa, optó por el verso y no hizo de la situación política o militar la materia de su escritura, pero sin duda esta quedó claramente reflejada en sus impresos en lo que toca al modo en que afectó su situación personal. Es en dicho contexto en el que se debe atender a lo específico de su representación en efigie.

Para su retrato apela a los mecanismos habituales en la representación de la autoridad, coincidiendo en ello con la habitual funcionalidad política y su empleo de los códigos inherentes al dominio de unos seres humanos sobre otros, en tanto el arte del retrato fue instrumentalizado por el estamento dominante hasta convertirlo en un aparejo más del poder. No es el caso de Rebolledo, o solo lo es en parte, ya que su mirada estaba menos atenta al impacto de su obra entre el público indiscriminado que al efecto ante unos destinatarios privilegiados, con la capacidad de mejorar su situación. En los 
paratextos en que se incluye su retrato predomina el tono de la dedicatoria, entre la exaltación del poderoso y el lamento por su estado personal (infra), y esta relación se proyecta en el tratamiento de las representaciones plásticas. El del autor no puede por ello incorporar una imagen de dominio, sino que su señorío tiene que venir templado por la posición ante el mecenas, pero a esta actitud de sentido común Rebolledo suma una particularidad, la de acompañar su retrato con el de la persona a quien se dedica el libro.

\section{Dedicatarias en efigie}

Ya ha quedado apuntado que dentro de la sistemática práctica de las dedicatorias por parte de Rebolledo (salvo en la primera edición de los Ocios ${ }^{5}$ ) hay dos rasgos destacables: la relativa abundancia de dedicatarias femeninas y las alteraciones introducidas en la reedición de sus obras, momento en que algunas de ellas cambian de destinatario, como quedó señalado. Con la reedición de los Ocios, dedicada a Sofía Amalia de Lüneburg, suma una obra más dirigida a una dama de la nobleza real, junto a Mariana de Austria (el Idilio sacro en sus dos ediciones) y el caso singular de Cristina de Suecia, a la que dirige en sus dos ediciones la paráfrasis de Job, La constancia victoriosa, con la versión de los trenos de Jeremías, textos especialmente idóneos para un momento de crisis espiritual como el que vivía la soberana.

Una de las facetas más curiosas y conocidas de la actividad diplomática de Rebolledo fue su relación con la reina Cristina de Suecia y la correspondencia que mantuvo con ella (González Cañal I986) ${ }^{6}$. La monarca, de educación luterana, asume el gobierno de Suecia con I8 años, en I644, y muy pronto manifiesta una crisis de fe, de gran trascendencia en el contexto de las luchas de religión que en estos momentos dividían Europa. Cristina se rodea de sabios e intelectuales; entre ellos destaca Descartes, católico en una corte contraria a esta religión, que parece ser tuvo mucho que ver en la conversión de la reina ${ }^{7}$. Cristina, finalmente, abdica de su corona para convertirse al catolicismo, hecho que causa una gran expectación en toda Europa, y en especial en la sociedad española, por su repercusión en el desarrollo de la contienda bélica y por la posible intervención en este hecho de Felipe IV y de sus embajadores. El conde de Rebolledo, como embajador en Copenhague, debió de tener una considerable influencia en la decisión

\footnotetext{
5 En su primer texto impreso solo aparece un prólogo «a quien leyere» del licenciado Isidro Flórez de Laviada, el secretario que aparece como responsable de la edición.

6 Puede recomponerse el contexto de esta relación con los trabajos recogidos por Martínez Ruiz y Pazzis Pi Corrales (2000).

7 «Los primeros pasos para la conversión de Cristina se deben a un jesuita portugués Antonio Macedo, confesor del embajador de Portugal, José Pinto Pereira, que llegó a Estocolmo en I65I» según el Marqués de Villa-Urrutia (González Cañal I986: 96).
} 
de la reina. Fue el primer español en contactar con ella, tras las dudas religiosas que la invadían, y, aunque no llegaron a conocerse personalmente, ya que este nunca fue a Suecia a causa de sus enfermedades, mantuvieron correspondencia hasta la abdicación de Cristina ${ }^{8}$. Tal fue su contacto con la soberana, que esta le otorgó la insignia y banda de la Orden de Amaranta.

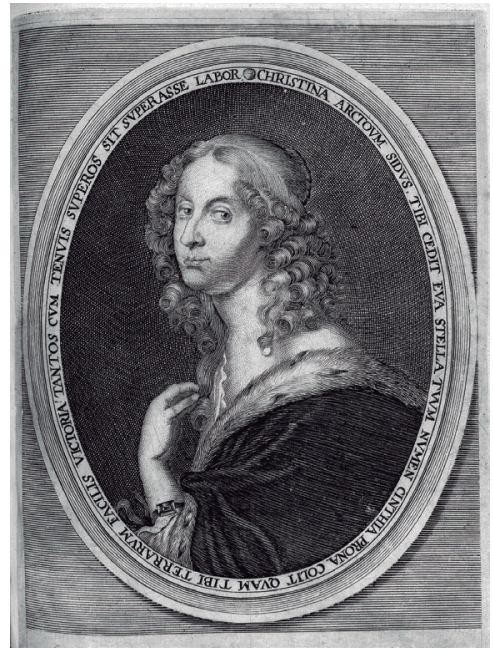

La constancia victoriosa, $\mathrm{I} 655$.

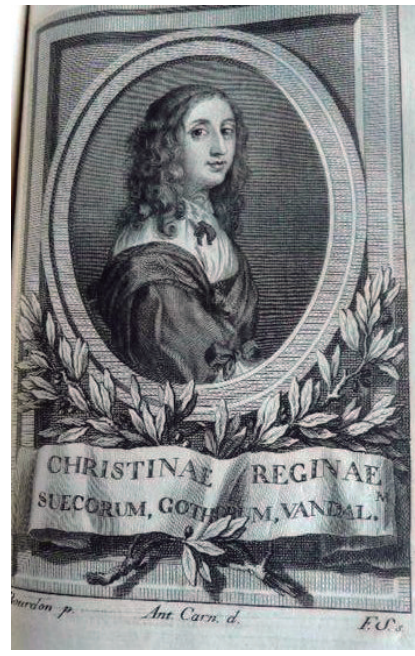

Selva sagrada, $\mathbf{1 7 7 8}$.

Rebolledo publica en Colonia La constancia victoriosa, y dedica esta obra a Cristina, incluyendo un retrato de la reina, además del suyo propio. Al reeditar el conjunto de su producción poética mantiene la dedicatoria y el

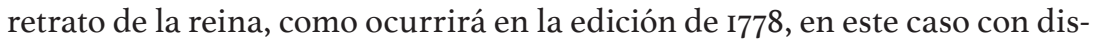
tinta estampa. Los dos grabados ofrecen una representación parecida en sus rasgos esenciales, con el busto de la monarca en edad adulta, representada en tres cuartos, casi de perfil, aunque su cabeza se encuentra levemente girada, pero hacia lados distintos en cada representación.

Encontramos una imagen del personaje muy humanizada, que no muestra artificios más allá de un ropaje elegante, careciendo de elementos o signos que muestren su condición regia, como corona o joyas. En la primera imagen encontramos un retrato muy íntimo, en el que la dama parece en-

8 En la carta dirigida al canónigo de la Catedral de León, fechada en Copenhague el 30 de marzo de I656, Rebolledo cuenta su relación con la Reina y los méritos que causan su intervención en el proceso de conversión de la monarca. En el romance 63 de los Ocios Rebolledo lamenta no poder asistir a la llamada de la reina: «Que yo en querelloso acento / articularé suspiros / en que el dolor se derrame / de no poderla haber visto». 
contrarse en un estado de introspección, que nos sugiere, quizá, ese proceso de conversión a la fe católica. La cercanía de su mano al pecho, que parece estar agarrando algo que cuelga de su cuello, posiblemente una medalla o un crucifijo, aumenta la sensación de encontrarse en posición de recogimiento hacia su mundo interior. En cambio, en el segundo grabado la soberana está en una pose ligeramente más regia y distante, aunque sin perder ese aura de intimidad que nos lleva a sentirla evadida en sus pensamientos. En ambos retratos los ojos almendrados dulcifican la mirada de la retratada, que se muestra observando al espectador, y su nariz alargada y la media sonrisa de sus labios hacen que la expresión de su rostro sea relajada y complaciente. Encontramos a la retratada en los dos casos centrada y dominando la composición, formando un triángulo cuyo vértice superior está en la cabeza, metáfora de cercanía o unión con Dios. Y aunque ambos están enmarcados en un medallón (al igual que los retratos de Rebolledo), en el primero la orla no tiene ornamentación, más que un texto que describe su estatus o condición, y en el segundo el texto descriptivo aparece debajo de la orla junto a hojas de laurel.

En la dedicatoria en verso de la paráfrasis bíblica es posible leer entre líneas un estímulo dirigido hacia su conversión al catolicismo, exaltando el valor del destino al que se dirigen las cavilaciones regias:

\author{
DEDICATORIA \\ Minerva que a las márgenes del Méler \\ pasaste los laureles del Peneo, \\ que se arrojaron ambiciosamente \\ a ceñir el Olimpo de tu frente \\ $\mathrm{y}$ te siguen en forma de trofeo \\ por la difícil vía \\ que te conduce la filosofía \\ al portátil Liceo, \\ de tanta erudición feliz empleo, \\ estos sagrados números dedico, \\ don en su original de todo rico, \\ y en que con evidencia \\ resplandece la suma providencia. \\ Trasladelos forzado \\ del poco menos lastimoso estado \\ que me secresta las demás acciones, \\ y voluntariamente los consagro \\ al divino milagro \\ de humanas perfeciones, \\ a cuyas siempre vitoriosas plantas, \\ que adornan tres coronas \\ y el cetro del Imperio soberano,
}


de que se despojó la docta mano, tributa el orbe generosas palmas, en inmortal dominio de las almas.

Con la referencia del personaje veterotestamentario convertido en emblema de desgracias y paciencia, el diplomático poeta parece establecer una similitud o, al menos, un espacio de confluencia con la reina, aunando con las de Job las tribulaciones derivadas del alejamiento de la patria y de la crisis de fe. La neoestoica constancia o fortaleza de ánimo, convertida en ataraxia y serenidad, parece ser la que se trata de plasmar en la expresión del retrato.

Sin embargo, pese a la importancia de su tarea, el embajador no eclipsa del todo al autor preocupado por su imagen y por el papel que en su valoración juega la representación icónica. Así, no falta una referencia metaartística al incluir un poema al retrato, que enlaza arte y valor pragmático ante la dedicataria:
¡Oh, si el Arte llegara
por medio del pincel más excelente
del ánimo a copiar las perfeciones!
Puesto que fuera tan confusamente como las del semblante nos declara, ¡cuánto más el retrato se estimara!
CRISTINA, de las Árticas Regiones
la cristiana Belona, divina Musa, soberana Gracia, las más rebeldes almas aprisiona con amable violencia, sin que tenga lugar la resistencia en lazos de dulcísima eficacia. $Y$ en igual competencia sus ojos, sus discursos, sus acciones triunfan de los más libres corazones.

La alabanza a la reina (también en su condición de musa) y a su retrato encierra oblicuamente un similar gesto ante su propia labor como poeta (imitador o pintor de los sufrimientos de Job) y una implícita llamada de atención a su propio retrato. En el gesto el efecto de la contigüidad de las dos imágenes se ve ratificado por un discurso en que se entrelazan las relaciones de escritor y dedicataria en una diversidad de facetas.

Un breve rodeo por un caso de dedicatario masculino puede confirmar este juego de Rebolledo con los retratos. La Selva sagrada es una traducción completa del Salterio de David dedicada a Felipe IV, publicada inicialmente en I657. Aunque no contiene un retrato del Rey, la representación alegórica 
del cisne de alas desplegadas extiende el aura de nobleza al escudo nobiliario de la portada y añade la alusión a la condición poética. En cambio, en las Rimas sacras, el tercer tomo de la reedición de las obras, encontramos un retrato del dedicatario. La representación de Felipe IV es sobria y austera. Su representación muestra más elementos de identidad con la del conde (atuendo, fondo de cortinas y ventana al exterior...) que diferencias. La similitud se refuerza en comparación con la imagen de la reedición dieciochesca. El rey aparece representado en un busto a tres cuartos, levemente girado, con gesto señorial. Sus ropajes y su porte denotan una imagen regia. Se trata de una representación prototípica, en la que el personaje se encuentra enmarcado en un medallón clásico que se encuentra ornamentado con diferentes elementos y atributos que aportan valor a su representación, como el medallón que aparece en su pecho, o la corona, la espada, el cojín y el catalejo en la parte baja del retrato, mostrando su categoría de rey y de hombre de armas. El dedicatario se encuentra enmarcado en la composición sobre un texto que lo identifica en su condición de soberano. En este caso, la relación difiere, y más que la de cercanía parece imponerse la imagen de distancia o de separación en los papeles que corresponden al poderoso y al escritor.

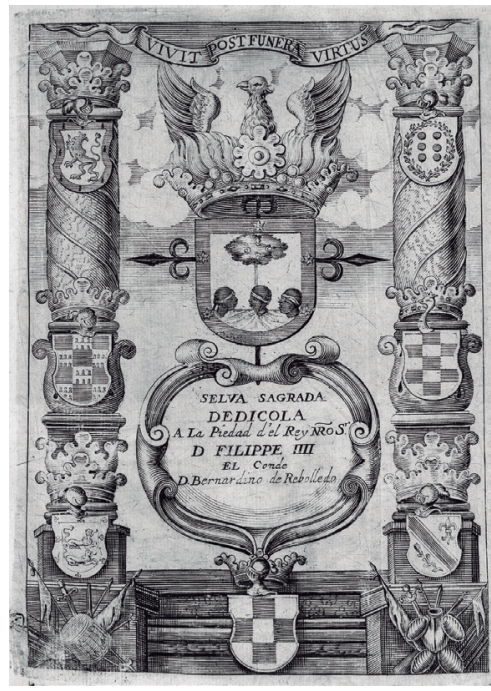

Selva sagrada, $\mathrm{I} 657$.

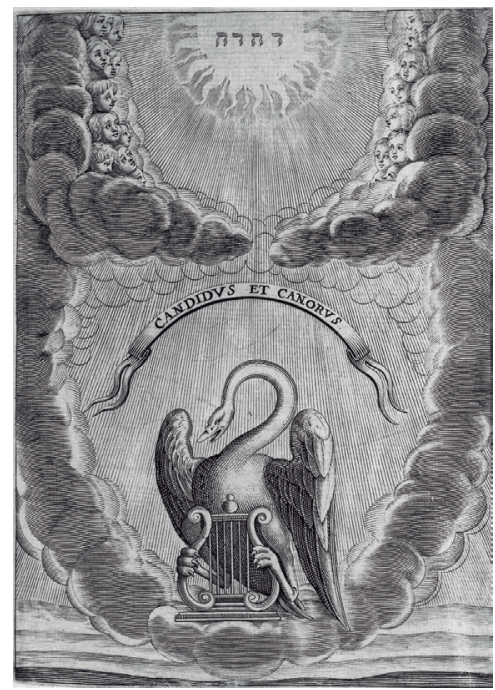

Selva sagrada, 1657 . 


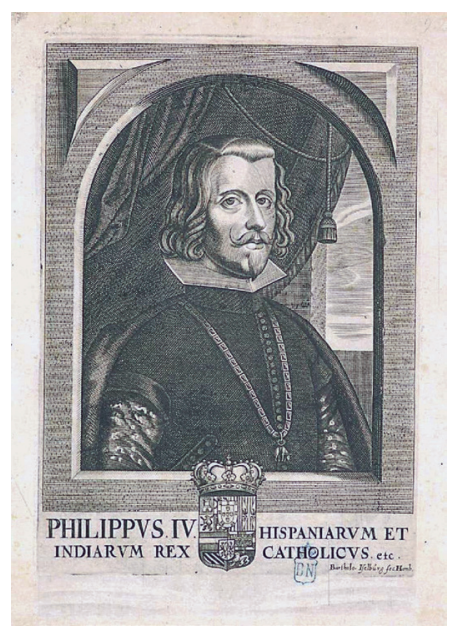

Rimas sacras, I66I.

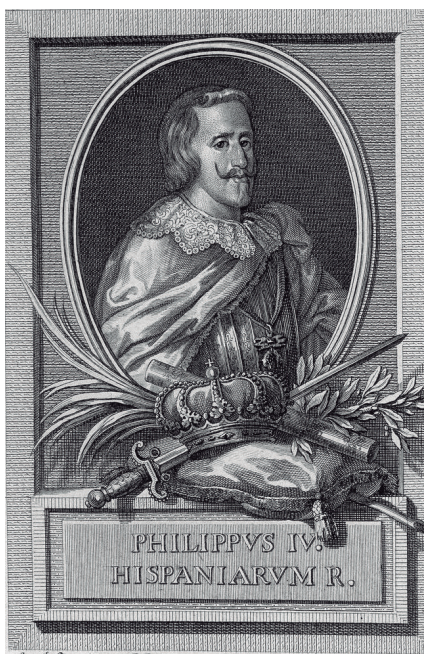

Rimas sacras, $\mathbf{I} 778$.

Caso distinto, como a medio camino entre las dos relaciones anteriores, es el de las dedicatorias a la reina Sofía Amalia, reiterada en la reedición de las Selvas dánicas y sumada en la de Ocios. Aunque comparte algunos rasgos iconográficos con el retrato de Mariana de Austria en Idilio sacro (la orla en medallón, la pose, el peinado y las vestiduras lujosas), las diferencias son significativas. 


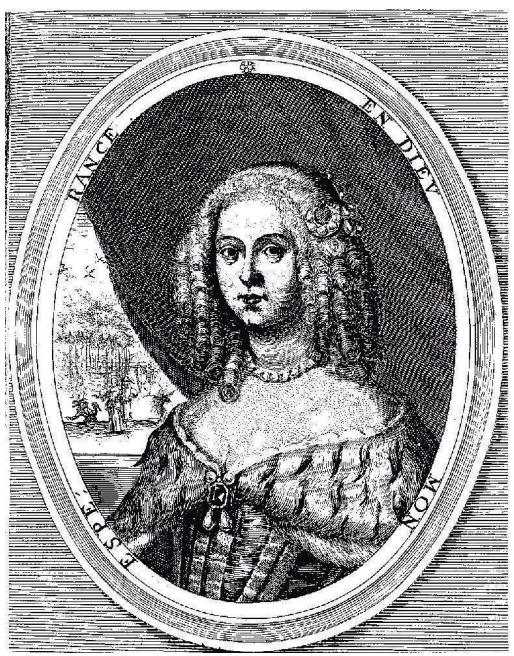

Ocios, I660.

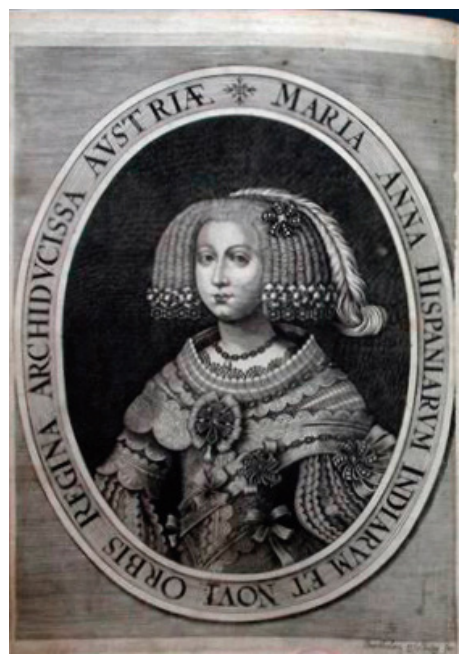

Idilio sacro, $\mathrm{I} 660$.

El hieratismo de la monarca hispana se manifiesta en la rigidez y recato de su vestido, en el adorno del peinado y, sobre todo, en el gesto serio, con una mirada al espectador que traslada idea de dominio; en el fondo del retrato domina un color negro, sin otros elementos, con una sobriedad impuesta en la corte de los Austria desde Felipe II. En el retrato de la reina danesa, dentro de un esquema iconográfico repetido, la imagen se distancia: el vestido deja ver sensualmente los hombros y, junto a la sencillez (relativa) del peinado y la dulzura derivada de una mirada perdida, denota una imagen más cercana, entre la intimidad y la complicidad, acordes con la estancia de Rebolledo en el palacio de la reina. Sobre todo destaca el detalle del fondo del retrato: como a través de una cortina descorrida se deja ver un jardín, sustituyendo la sobriedad por la sensorialidad. En alusión a la silva descriptiva de la segunda parte de la obra, el grabado conecta el texto con el palacio de Hersholme, sinécdoque de la reina y asunto del texto. Así, mientras en la relación con los monarcas hispanos, el poeta se mantiene en una posición tradicional respecto al mecenas poderoso, sin distinción por la condición sexual de la figura regia, cuando se trata de ocupantes femeninas de tronos con los que no tiene relación de servidumbre el juego de comunicación se modifica y se manifiesta en el tratamiento de las representaciones icónicas. 


\section{A modo de conclusión}

El retrato de Rebolledo en los paratextos de sus obras, además de por su sistematicidad, avanza sobre el uso que se estaba extendiendo entre otros autores. Por un lado, revela el interés en destacar su condición nobiliaria, motivado por la concepción elevada de su obra y por la funcionalidad pragmática que quería otorgarle como instrumento en sus tareas diplomáticas. En su afán de reconocimiento intelectual en clave de modernidad, el poeta afirma la autoría de la obra y su papel de escritor, convirtiendo el retrato en una firma de prestigio. Por otro lado, la inclusión de las imágenes de sus dedicatarios revela la conciencia de la relación entre el sujeto y la institución, pues siempre se trata de destinatarios regios. En su gramática visual y su función pragmática, Rebolledo articula en el juego de retratos unas estrategias en el espacio de recepción a partir de distintos modos de equiparación, comenzando por la similitud iconográfica. No sobresale una representación por encima de la otra, y ambas mantienen un protagonismo paralelo. La situación se intensifica en el caso de las dedicatarias con las que no mantiene vínculos de raíz feudal, pues la distancia es sustituida por un espacio, espiritual o físico, compartido. A partir de la similitud de los retratos, Rebolledo matiza la relación de mecenazgo e introduce en ella, en el caso de las reinas nórdicas, una relación más horizontal, convertida en clave de lectura. El empleo de un lenguaje visual compartido solventa las indiscutibles diferencias de cuna con un juego en el que la capacidad intelectual y emotiva desplaza el marco de sumisión y plantea un correlato con el lector y un espacio de autonomía para la obra.

Con el evidente dominio por el poeta diplomático de sus posibilidades expresivas y pragmáticas, el retrato, en definitiva, enlaza a los participantes en la comunicación poética y establece de una manera muy material y perceptible unas relaciones que no son estrictamente las del mecenazgo, más bien las de un diálogo intelectual en que la autoridad de la realeza se pone en relación con la autoría del poeta, pero también se abre a nuevas posibilidades para la comunicación de este con su lector: con la lectora privilegiada que aparece en el grabado, pero también con el resto de lectores del libro que asisten a esta propuesta de diálogo entre lo visual y lo poético.

\section{Bibliografía}

Bourdieu, Pierre, Las reglas del arte: génesis y estructura del campo literario, Barcelona, Anagrama, 1995.

Brown, Cynthia J., Poets, Patrons, and Printers: Crisis of Authority in Late Medieval France, Ithaca, Cornell University, 1995. 
Camoens, Luis de, Lusiadas de Luis de Camoens, príncipe de los poetas de Espa$\tilde{n} a$, al rey nuestro señor Felipe Cuarto el Grande, comentadas por Manuel de Faria y Sousa, ed. Juan Sánchez, primero y segundo tomo, Madrid, Juan Sánchez, I639.

Ezell, M.J.M., Social Authorship and the Advent of Print, Baltimore, The Johns Hopkins University, I999.

González Cañal, Rafael, «El conde de Rebolledo y la reina Cristina de Suecia: una amistad olvidada», Tierras de León, 26.62, I986, pp. 93-I08.

- Edición crítica de los «Ocios» del Conde de Rebolledo, Cuenca, Universidad de Castilla-La Mancha, 1997.

—. «Rebolledo, Bernardino de, conde de», en Diccionario filológico de literatura española. Siglo XVII, dir. Pablo Jauralde Pou, Madrid, Castalia, 20Io, v. I, pp. 248-252.

Grafton, Anthony \& Lisa Jardine, From Humanism to the Humanities: Education and the Liberal Arts in Fifteenth- and Sixteenth-Century Europe, Londres, Duckworth, 1986.

Jiménez Belmonte, Javier, Las «Obras en verso» del Príncipe de Esquilache: amateurismo y conciencia literaria, Woodbridge, Tamesis, 2007.

López de Sedano, Juan José, Parnaso español. Colección de poesías escogidas de los más célebres poetas castellanos, tomo V, Madrid, Joaquín Ibarra, I77I.

Martín Puya, Ana Isabel, «Periferias de un noble: el conde de Rebolledo», en Heterodoxias y Periferias: La Poesía Hispánica en el Bajo Barroco, eds. Itzíar López Guil, Adrián J. Sáez, Antonio Sánchez Jiménez y Pedro Ruiz Pérez, monográfico de Versants. Revista Suiza de Literaturas Románicas, 60.3, 20I3, pp. II9-I29.

Martínez Ruiz, Enrique \& Magdalena de Pazzis Pi Corrales (dirs.), Spain E Sweden in the Baroque Era (I60o-I660), Madrid, Fundación Berndt Wistedt, 2000.

Pellicer, José de, Lecciones solemnes a las obras de dos Luis de Góngora y Argote, Madrid, Imprenta del Reino, I630 (http://www.cervantesvirtual.com/ obra/lecciones-solemnes-a-las-obras-de-don-luis-de-gongora-y-argote--o/).

Ruiz Pérez, Pedro, La rúbrica del poeta. La expresión de la autoconciencia poética de Boscán a Góngora, Valladolid, Universidad de Valladolid, 2009.

—. «Modelos editoriales y perfiles de autor tras el canon áureo (I650-I700)», en Tras el canon. La poesía del Barroco tardío, ed. Ignacio García Aguilar, Vigo, Academia del Hispanismo, 2009b, pp. I09-I24.

—. «La edición zaragozana a mediados del siglo XVII y la sistematización del libro», coord. Pedro Ruiz Pérez, monográfico del Bulletin Hispanique, II3.I, 20II, pp. 69-IOI (http://bulletinhispanique.revues.org/I3I6).

-. «Visión y mirada en las Selvas dánicas del conde de Rebolledo», Creneida, 2, 20I4, pp. 349-374 (http://www.creneida.com/revista/creneida-2-20I4/ 
visión-y-mirada-en-las-selvas-dánicas-del-conde-de-rebolledo-pedroruiz-pérez/).

—. «Vision and gaze in Rebolledo's Selvas dánicas», en Mirabiliratio. Das Wunderbare im Zugriff der Frühneuzeitlichen Vernunft, eds. Christoph Strosetzki y Dominique de Courcelles, Heidelberg, Universitätsverlag / Winter, 2015, pp. 26I-279.

—. «Carreras recompuestas: publicaciones póstumas y sujeto editorial», en Carrera literaria y representación autorial en la literatura del Siglo de Oro, eds. Juan Montero y Antonio Sánchez Jiménez, monográfico en eHumanista, 35, 20I7, pp. IOO-I26 (http://www.ehumanista.ucsb.edu/sites/secure. lsit.ucsb.edu.span.d7_eh/files/sitefiles/ehumanista/volume35/monographI/I0\%2oehum35.as.ruiz\%2ope\%CC\%8Irez.pdf).

—. «Fragmentos del ocio: edición y reescritura en el bajo barroco», en Serenísima palabra. Actas del X Congreso de la Asociación Internacional Siglo de Oro, eds. Anna Bognolo, Florencio del Barrio de la Rosa, Ma Valle Ojeda Calvo, Donnatella Pinni y Andrea Zinato, Venezia, Edizioni Ca' Foscari, 20I7b, t. I, pp. $32 \mathrm{I}-330$ (http://edizionicafoscari.unive.it/it/edizioni/libri/978-88-6969-I64-5/fragmentos-del-ocio-edicion-y-reescritura-en-el$\mathrm{ba} /)$.

Sánchez Jiménez, Antonio, Lope pintado por sí mismo: mito e imagen del autor en la poesía de Lope de Vega Carpio, Woodbridge, Tamesis, 2006.

Sociología de la literatura hispánica: el autor y la institución literaria, coord. Pedro Ruiz Pérez, monográfico de Studi Ispanici, XLIII, 2018.

Strosetzki, Christoph, La literatura como profesión. En torno a la autoconcepción de la existencia erudita y literaria en el Siglo de Oro español, Kassel, Reichenberger, 1997. 